\title{
A novel minimally invasive, dorsolateral, tubular partial odontoidectomy and autologous bone augmentation to treat dens pseudarthrosis: cadaveric, 3D virtual simulation study and technical report
}

\author{
Eleftherios Archavlis, MD, ${ }^{1}$ Lucas Serrano, MD, ${ }^{1}$ Eike Schwandt, MD, ${ }^{1}$ Amr Nimer, MD, ${ }^{1}$ \\ Moisés Felipe Molina-Fuentes, MD, ${ }^{2}$ Tamim Rahim, MD, ${ }^{3}$ Maximilian Ackermann, MD, ${ }^{4}$ \\ Angelika Gutenberg, MD, ${ }^{1}$ Sven Rainer Kantelhardt, MD, ${ }^{1}$ and Alf Giese, MD ${ }^{1}$ \\ ${ }^{1}$ Department of Neurosurgery and ${ }^{4}$ Institute of Anatomy, University Medical Center, Johannes Gutenberg-University Mainz;
'Department of Neurosurgery, University Hospital Halle (Saale); and ${ }^{3}$ Neurosurgical Practice, Wiesbaden, Germany
}

OBJECTIVE The goal of this study was to demonstrate the clinical and technical nuances of a minimally invasive, dorsolateral, tubular approach for partial odontoidectomy, autologous bone augmentation, and temporary $\mathrm{C} 1-2$ fixation to treat dens pseudarthrosis.

METHODS A cadaveric feasibility study, a 3D virtual reality reconstruction study, and the subsequent application of this approach in 2 clinical cases are reported. Eight procedures were completed in 4 human cadavers. A minimally invasive, dorsolateral, tubular approach for odontoidectomy was performed with the aid of a tubular retraction system, using a posterolateral incision and an oblique approach angle. Fluoroscopy and postprocedural CT, using 3D volumetric averaging software, were used to evaluate the degree of bone removal of C1-2 lateral masses and the C-2 pars interarticularis. Two clinical cases were treated using the approach: a 23-year-old patient with an odontoid fracture and pseudarthrosis, and a 35-year-old patient with a history of failed conservative treatment for odontoid fracture.

RESULTS At 8 cadaveric levels, the mean volumetric bone removal of the C1-2 lateral masses on 1 side was $3 \% \pm 1 \%$, and the mean resection of the pars interarticularis on 1 side was $2 \% \pm 1 \%$. The median angulation of the trajectory was $50^{\circ}$, and the median distance from the midline of the incision entry point on the skin surface was $67 \mathrm{~mm}$. The authors measured the diameter of the working channel in relation to head positioning and assessed a greater working corridor of $12 \pm 4 \mathrm{~mm}$ in $20^{\circ}$ inclination, $15^{\circ}$ contralateral rotation, and $5^{\circ}$ lateral flexion to the contralateral side. There were no violations of the dura. The reliability of C-2 pedicle screws and C- 1 lateral mass screws was $94 \%$ ( 15 of 16 screws) with a single lateral breach. The patients treated experienced excellent clinical outcomes.

CONCLUSIONS A minimally invasive, dorsolateral, tubular odontoidectomy and autologous bone augmentation combined with C1-2 instrumentation has the ability to provide excellent 1-stage management of an odontoid pseudarthrosis. The procedure can be completed safely and successfully with minimal blood loss and little associated morbidity. This approach has the potential to provide not only a less invasive approach but also a function-preserving option to treat complex C1-2 anterior disease.

https://thejns.org/doi/abs/10.3171/2016.7.SPINE16244

KEY WORDS minimally invasive; odontoidectomy; dens pseudarthrosis; dens fracture; tubular; cervical; surgical technique

$\mathrm{T}$ HE surgical management of a dens-axis nonunion can often be challenging. ${ }^{15,21,31,33}$ In many cases, anterior or posterior instrumentation may be indicated for failed conservative or operative treatment of dens fracture. ${ }^{14,18,23,28}$ When there is instability and the patient is symptomatic, surgical intervention is often needed to manage the local mechanical pain and to prevent either actual or impending neurological deficit. Furthermore, in cases in which the instability is extensive, there might be a severe dislocation of the dens. In these cases, the prevention of impending mechanical instability and progressive neurological damage due to myelopathy is critical. ${ }^{7,8,11,26}$ 
C1-2 fusion is generally recommended to restore stability. A variety of techniques for posterior stabilization have been described, including the wiring techniques of Gallie or Brooks and Jenkins, ${ }^{6,13}$ the transarticular Magerl screw fixation of C1-2 with or without supplemental wiring,,$^{17,30}$ and posterior $\mathrm{C} 1-2$ fusion with screw-rod instrumentation in the technique of Harms and Melcher. ${ }^{16}$ These approaches provide excellent mechanical stability, reconstruction, and correction of any dislocations. Despite these advantages, the C1-2 posterior stabilization remains an operation associated with arthrodesis and loss of function, especially limitation of rotation. ${ }^{27}$

More recently, Harms and his group described an innovative surgical technique that entails anterior cancellous bone augmentation of the dens axis and temporary fixation of $\mathrm{Cl}-2$, which restores stability while preserving mobility of the atlantoaxial joint. However, this is a demanding surgical procedure requiring 2 and sometimes 3 exposures and is associated with a not inconsiderable complication rate. ${ }^{27}$

In cases of irreducible atlantoaxial dislocations, a transoral anterior atlantoaxial release and posterior internal fixation could provide reduction and stabilization, but the approach-related morbidities associated with this technique can be significant. ${ }^{34}$ The incorporation of evolving minimally invasive access techniques has the potential to minimize associated morbidities without compromising the goals of surgery. The goal of this report is to describe the innovative application of a minimally invasive access technique to partial odontoidectomy of the pseudarthrotic area, which entails cancellous bone augmentation of the dens axis via a posterolateral route. This technique enables the 1-stage temporary fixation of $\mathrm{C} 1-2$, which restores stability while preserving mobility of the atlantoaxial joint. We describe the procedure in 3D virtual reality and cadaveric models, and subsequently in 2 clinical cases.

\section{Methods}

\section{Cadaveric and 3D Virtual Reality Procedures}

A total of 8 surgical procedures were performed in 4 cadavers. The aim of the operation in each cadaver was a partial odontoidectomy of a fictive dens pseudarthrosis and C1-2 instrumentation as described by Harms and Melcher, and modified in a minimally invasive technique by our group. ${ }^{19}$ Before surgery, a 3D virtual reality reconstruction study was performed on the Dextroscope (Volume Interactions, Ltd.). Cadaveric dissections were undertaken with the cadaver in the prone position. The level and position were confirmed with the use of portable $\mathrm{C}$-arm guidance (Pulsera, Phillips). A tubular dilation access system (METRx, Medtronic) was used, and a final miniopen retractor system (10 mm; Aesculap Spine Classic, B. Braun) was placed far obliquely at each operative side. A minimally invasive resection of the dens middle zone was completed, and autologous bone was placed under direct visual and fluoroscopic guidance. Lateral mass screws and pedicle screws were placed at C-1 and C-2, respectively.

In all specimens, pre- and postprocedural CT scans were obtained with 1-mm axial sequences. Using 3D volumetric averaging software (Dextroscope), we evaluated the trajectory, angle of approach, best working-channel diameter, head positioning, and degree of bone removal of C1-2 lateral masses and C-2 pars interarticularis. Using spinal neuronavigation (Patient Browser 2.0, BrainLAB) based on the 3D virtual reality reconstruction software (Dextroscope) we performed a partial odontoidectomy of the dens middle zone, simulating resection of a dens pseudarthrosis. Sequential steps of the fictive procedure on the Dextroscope are shown in Fig. 1.

Intraoperatively and postoperatively, the dura mater and the vertebral artery were evaluated for evidence of injury. Findings from the comparisons of preoperative planning and postoperative images were used to determine the reliability of the procedure. Furthermore, cross-sectional imaging was used to determine the accuracy of minimally invasive resection of the simulated dens pseudarthrosis and the accuracy of the C1-2 lateral mass and pedicle screws in all specimens. The volumetric removal of the C1-2 lateral mass and C-2 pars interarticularis and the percentage of odontoidectomy was calculated using the above-mentioned 3D reconstructive imaging software.

\section{Clinical Cases}

Using BrainLAB navigation and fluoroscopic guidance in 2 cases, a $3.5-\mathrm{cm}$ incision was made 5-7 cm off midline according to the preoperative planning measurements. A pointer was then inserted through the posterior occipitocervical musculature and docked on the C1-2 atlantoaxial articulation. Sequential soft-tissue tubular dilators were used to separate the posterior musculature. A tubular 11-mm-wide retractor was placed over the final dilator, and residual soft tissue was removed under microscopic guidance. The ipsilateral lamina of C-1, pars interarticularis of $\mathrm{C}-2, \mathrm{C} 1-2$ facet of the lateral atlantoaxial articulation, and C-2 nerve root were exposed. A subperiosteal dissection was performed to expose the $\mathrm{C} 1-2$ atlantoaxial joint. The transverse process, facet, and lamina, and especially the bony walls of the vertebral artery were kept intact, and soft tissues were detached from the bone structures. The C-2 nerve root was ligated using hemostatic clips (Weck, Tefelex Medical, Inc.) and was cut. A light retraction of the dural sac between the C-2 ganglion and the antlantoaxial articulation could be applied to expose the odontoid process. Cutting the C-2 nerve had no effect on function; thus the anterior radix was responsible for the innervation of the infrahyoid muscle and the posterior radix for the innervation of the skin and paravertebral muscles. ${ }^{20}$ The pseudarthrotic region of the odontoid process was then removed gradually with the combined use of a 4-mm-diameter high-speed drill, Kerrison rongeurs, and osteotomes. We used a nerve retractor to protect the dura and myelon from inadvertent injury while drilling. The anterior arch of the atlas and the transverse longitudinal ligament behind the dens axis were not removed during the odontoidectomy and were left in place to protect the future motion element of the C1-2 unit. The drill hole was then carefully packed with autologous cancellous bone. Biplanar C-arm control during this procedure was performed to avoid displacement of the pseudarthrosis and/or dislocation of bone graft material. During odontoid resection we obtained electrophysiological control using somatosensory evoked 

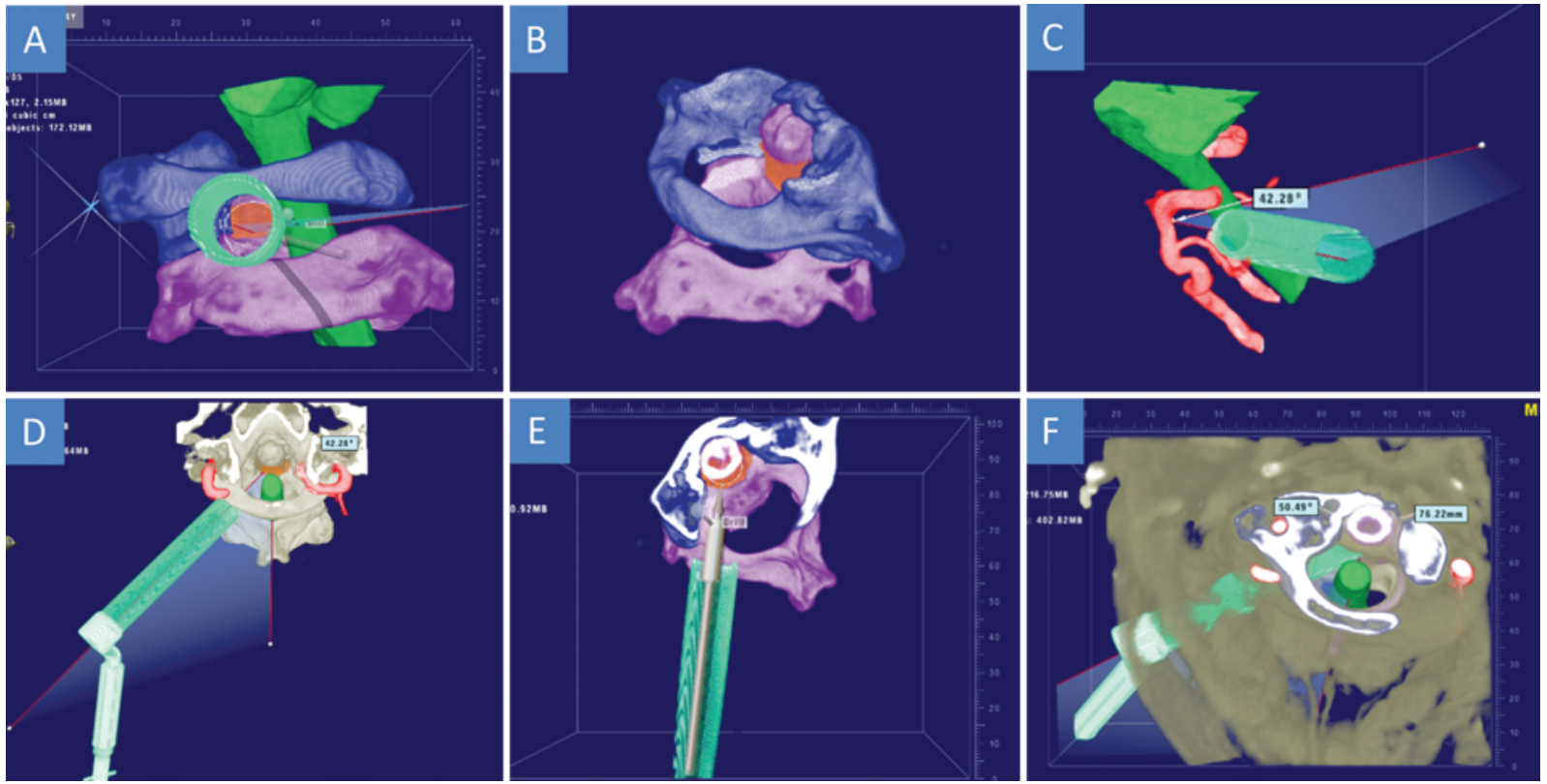

FIG. 1. Three-dimensional virtual reality reconstruction study on the Dextroscope. A: Posterolateral oblique approach angle for 1-stage pseudarthrosis resection/fusion and temporary instrumentation. B: Best working channel diameter according to head positioning. C: The retractor is placed in the "safe zone," and the relationship to the critical structures, vertebral artery, and myelon is demonstrated. D: Evaluation of the trajectory and angle of approach. E: Evaluation of the degree of bone removal of C1-2 lateral masses and C-2 pars interarticularis. F: Working corridor with maintenance of the lateral mass and C1-2 joint, respecting critical structures and enabling C1-2 arthrodesis (using the Harms technique) temporarily. The C-2 nerve was cut on 1 side.

potentials and motor evoked potentials of all extremities. Reduction of the odontoid was achieved by direct manipulation or via halo distraction.

Using the same approach on the ipsilateral side and under BrainLAB navigation and $\mathrm{C}$-arm fluoroscopic guidance, lateral mini-open $\mathrm{C} 1-2$ fixation (using $\mathrm{C}-2$ pedicle and C-1 lateral mass screws; Lineum, Biomet) was obtained. On the contralateral side, to obtain $\mathrm{C} 1-2$ fixation we also sought to minimize the invasiveness of the surgical treatment using a mini-open approach. The incision location was indicated by the navigation. Muscles were dissected bluntly, and a tubular retractor was inserted under navigational guidance. A detailed description of the percutaneous cervical instrumentation has been described previously by our group. ${ }^{19}$ Patients were examined 4 months postoperatively by conventional CT. Bone consolidation of the pseudarthrosis was confirmed, and temporary C1-2 instrumentation was removed to restore mobility of the C1-2 segment. The patient in Case 1 underwent a 6-week clinical rehabilitation, and in Case 2 a 4 -week clinical rehabilitation. We contacted Case 1 nine months and Case 2 seven months after the last surgery. Due to the fact that both patients are living abroad, we had a video consultation and also organized a clinical examination in cooperation with a spine surgeon near the place of residence. Both patients reported an uneventful recovery and satisfaction.

\section{Results}

\section{Cadaveric and 3D Virtual Reality Models}

A summary of the surgical results at 8 operative levels in 4 cadavers is presented in Table 1. This table lists the anatomical, fictive status of trajectory angulation, entry point distance from the midline, and target and postoperative changes in the bone and soft-tissue structures after surgery.

The median angulation of the trajectory was $50^{\circ}$, and the median distance from the midline of the incision entry point on the skin surface was $67 \mathrm{~mm}$. We measured the diameter of the working channel in relation to head positioning and assessed a mean greater working corridor of $12 \pm 4 \mathrm{~mm}$ in $20^{\circ}$ inclination, $15^{\circ}$ contralateral rotation, and $5^{\circ}$ lateral flexion to the contralateral side. At all sites of cadaveric dissection there was no evidence of violation into the dura or vertebral artery on inspection.

The mean volumetric bone removal of the $\mathrm{C} 1-2$ lateral masses on 1 side was $3 \% \pm 1 \%$, and the mean resection of the pars interarticularis on 1 side was $2 \% \pm 1 \%$. The reliability of the $\mathrm{C}-2$ pedicle screws and $\mathrm{C}-1$ lateral mass screws was $94 \%$ (15 of 16 screws) with a single lateral breach. The steps of the minimally invasive partial odontoidectomy in a representative cadaveric specimen are shown in Fig. 2.

\section{Clinical Cases}

In the 2 clinical cases of nonunion after fracture of the dens, surgery was performed after a 3D virtual reality reconstruction study. The estimated blood loss was $150 \mathrm{ml}$ in Case 1 and $260 \mathrm{ml}$ in Case 2, and the operative times were 2.8 and 3.1 hours, respectively. In both clinical cases there was evidence of significant restoration of the anatomical alignment at $\mathrm{C} 1-2$, and postoperative im- 
TABLE 1. Results of the 3D virtual reality and cadaveric study

\begin{tabular}{|c|c|c|c|c|c|c|c|c|}
\hline \multirow[b]{2}{*}{ Approaches } & \multicolumn{8}{|c|}{ Cadaveric Case } \\
\hline & 1 & 2 & 3 & 4 & 5 & 6 & 7 & 8 \\
\hline \multicolumn{9}{|l|}{ Bone removal (\%) } \\
\hline \multicolumn{9}{|l|}{ C-1 } \\
\hline Fictive & 3 & 2 & 3 & 4 & 2 & 3 & 3 & 2 \\
\hline Postop & 0 (no drilling) & 1 & 1 & 2 & 1 & 3 & 2 & 0 (no drilling) \\
\hline \multicolumn{9}{|l|}{$\mathrm{C}-2$} \\
\hline Fictive & 2 & 2 & 1 & 2 & 2 & 1 & 1 & 2 \\
\hline Postop & 2 & 1 & 1 & 2 & 2 & 1 & 1 & 2 \\
\hline \multicolumn{9}{|l|}{ Trajectory angulation $\left({ }^{\circ}\right)$} \\
\hline Fictive & 42 & 41 & 46 & 53 & 55 & 52 & 56 & 53 \\
\hline Intraop & 42 & 41 & 46 & 53 & 55 & 55 & 56 & 53 \\
\hline \multicolumn{9}{|c|}{ Entry point-median distance (mm) } \\
\hline Fictive & 60 & 59 & 58 & 61 & 59 & 60 & 62 & 68 \\
\hline Intraop & 60 & 59 & 58 & 61 & 59 & 60 & 62 & 68 \\
\hline \multicolumn{9}{|c|}{ Entry point-target distance (mm) } \\
\hline Fictive & 66 & 68 & 66 & 69 & 62 & 68 & 65 & 67 \\
\hline Intraop & 67 & 67 & 66 & 68 & 63 & 68 & 65 & 63 \\
\hline \multicolumn{9}{|l|}{ Working channel (mm) } \\
\hline Fictive & 11 & 12 & 13 & 12 & 13 & 11 & 13 & 12 \\
\hline Intraop & 11 & 12 & 13 & 12 & 13 & 11 & 13 & 12 \\
\hline \multicolumn{9}{|c|}{ Distance from risk structures (mm) } \\
\hline \multicolumn{9}{|l|}{ Distance from myelon } \\
\hline Fictive & 1 & 2 & 1 & 3 & 1 & 2 & 1 & 2 \\
\hline Intraop & 1 & 2 & 1 & 3 & 1 & 2 & 1 & 2 \\
\hline \multicolumn{9}{|c|}{ Distance from vertebral artery } \\
\hline Fictive & 3 & 4 & 3 & 5 & 3 & 6 & 4 & 5 \\
\hline Intraop & 3 & 4 & 3 & 5 & 3 & 6 & 4 & 5 \\
\hline
\end{tabular}

aging demonstrated sufficient placement of lateral mass and pedicle screw fixation. Both patients experienced an improvement in their postoperative course with less neck pain and less analgesic medication; the visual analog scale score for neck pain preoperatively was 7 in Case 1 and 8 in Case 2, and postoperatively after discharge was 2 in Case 1 and 3 in Case 2.

There were no major intraoperative complications, infections, or CSF leaks. Additionally, there was no evidence of misplaced hardware. We measured the range of motion of the cervical spine clinically in flexion-extension, side bending, and rotation after 4-6 weeks of clinical rehabilitation. We compared these results with the average values reported in the literature. Both patients achieved more than $80 \%$ of the normal values in all directions, especially in rotation. For Case 1, mobility of the cervical spine was $60^{\circ} / 50^{\circ}$ in flexion/extension, $35^{\circ} / 35^{\circ}$ in left/right lateral bending, and $70^{\circ} / 70^{\circ}$ in left/right rotation. For Case 2 we measured $65^{\circ} / 60^{\circ}$ in flexion/extension, $40^{\circ} / 40^{\circ}$ in left/ right lateral bending, and $75^{\circ} / 70^{\circ}$ in left/right rotation.

\section{Case 1}

This 23-year-old man suffered a motor vehicle accident and sustained a nonunion after conservative treatment of a fracture of the dens (Anderson and D'Alonzo classification
Type 2). The time interval between initial trauma and the minimally invasive instrumentation and bone augmentation was 3 years. The anterior dislocation of the odontoid process with the simultaneous forward movement of the atlas facet was very helpful for the exposure of the pseudarthrosis. Figure 3 shows the pre-, intra- and postoperative radiographs and $\mathrm{CT}$ scans. The patient was mobilized on the 1st postoperative day and had an uneventful recovery.

\section{Case 2}

This 35-year-old man sustained the initial C-2 fracture due to a fall from a roof. Conservative treatment of the Anderson and D'Alonzo Type 2 dens fracture with halo immobilization for 3 months failed to achieve fusion and the patient suffered intractable pain from instability and myelopathy. Minimally invasive resection of the pseudarthrosis and autologous bone augmentation was performed 2 years after the initial trauma (Fig. 4). The patient was mobilized directly after surgery and experienced no pain or neurological deficits postoperatively.

\section{Discussion}

Recent advances in the application of minimally invasive techniques have allowed many traditional spinal 

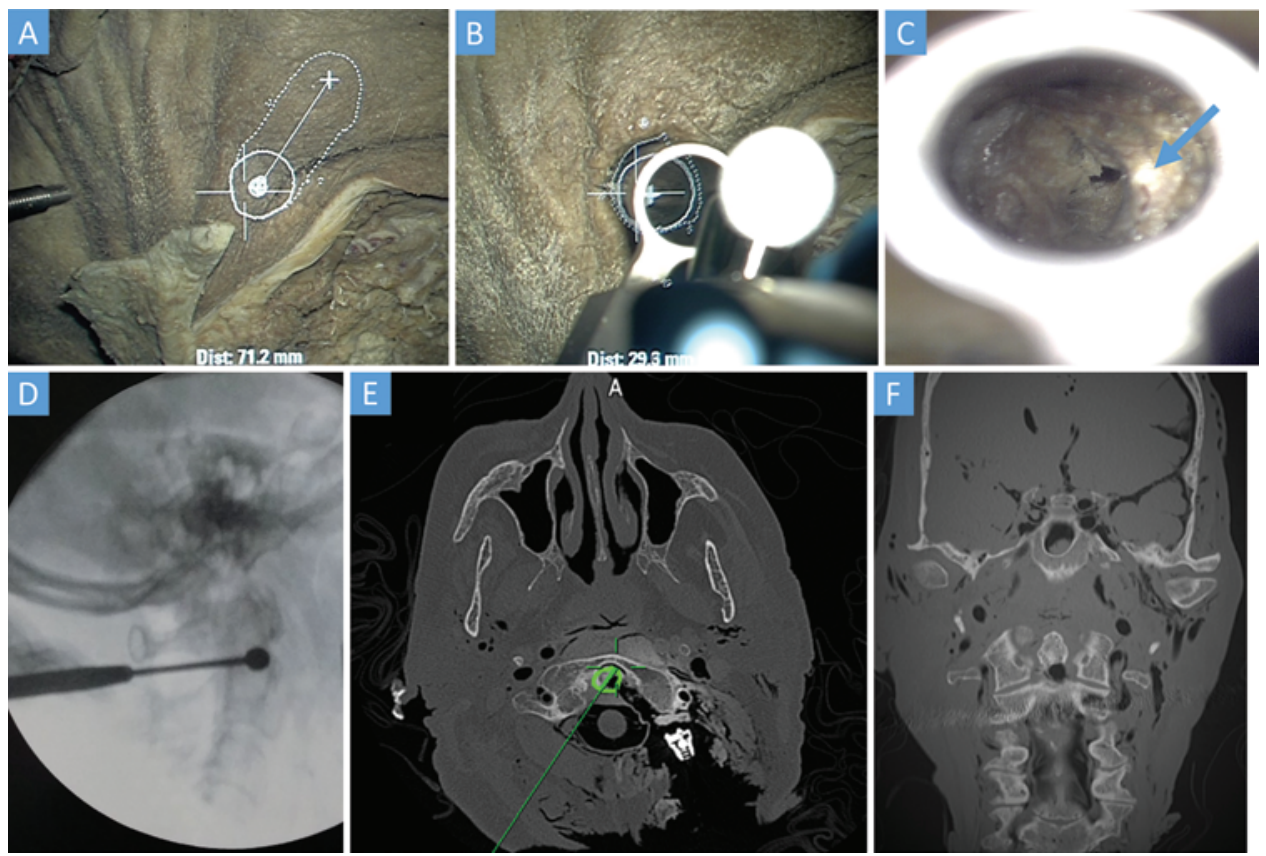

FIG. 2. Surgical approach on a cadaveric specimen. A: A 3-cm incision was made according to CT navigation data. B: Placement of the tubular retractor. C: Ligation and retraction of the C-2 nerve root (arrow). D and E: Guidance of the bur according to fluoroscopy (D) and CT navigation (green circle, E). F: Postoperative coronal CT scan shows the bone defect in the dens middle zone according to preplanning of the pseudarthrosis.

operations to be completed with a focus on minimizing injury to the soft tissue and decreasing blood loss. ${ }^{3}$ The role of minimal access techniques has progressively expanded to now include applications for multilevel arthrodesis and trauma management in the cervical spine. ${ }^{19}$ These techniques further complement more established minimal access techniques, including tubular microdiscectomy and lumbar decompression and fusion through mini-open approaches. The benefits of these minimally invasive procedures may include decreased pain and blood loss, and a reduced length of hospitalization.

The possibility of surgical treatment in odontoid nonunion remains controversial. ${ }^{4}$ However, in cases with significant instability, surgical intervention is generally recommended to avoid potentially serious complications through injury of the spinal cord. ${ }^{8,25,26}$ Different operative techniques focused on restoring stability and providing $\mathrm{C} 1-2$ fusion such as Gallie wiring, ${ }^{13}$ the sublaminar wiring of Brooks and Jenkins, ${ }^{6}$ and the transarticular screw stabilization of Magerl with or without wiring. ${ }^{17,30}$ The C1-2 fusion according to Harms and Melcher is the most established approach for pseudarthrosis after dens fracture. ${ }^{16}$ The primary benefit of this approach is that it provides excellent visualization and exposure of the bone structures and minimizes the incidence of vertebral artery damage during screw placement. However, it is well established that the approach-related morbidity associated C1-2 fusion is related to loss of function, namely approximately $50 \%$ of cervical rotation. Any attempts to preserve atlantoaxial mobility with direct anterior fixation and additional bone grafting have not achieved good union rates and have been discontinued. ${ }^{2,5,10}$ An innovative approach with fundamental improvement in odontoid fusion came from the group of Harms et al. Using a 3-stage surgery, Ruf et al. described a resection of pseudarthrosis from anterior and temporary stabilization from the posterior approach, and demonstrated excellent postoperative radiographic rates of $\mathrm{C} 1-2$ joint mobility. ${ }^{27}$ However, this is a demanding surgical procedure requiring 2 and sometimes 3 exposures and is associated with a not inconsiderable complication rate. In our procedure, odontoid fusion and temporary stabilization can be performed simultaneously and the complication rate can be relatively low. Limin et al. reported a posterolateral approach to occipitoatlantoaxial ventral lesions. ${ }^{22}$ This technique was used in 23 patients and involved a resection of the posterior arch of the atlas with wide exposure of the pathology and an occipitocervical spinal fusion. Duntze et al. described a minimally invasive approach to the dens and showed the feasibility of the endoscopic endonasal approach for its resection. ${ }^{9}$ However, this approach provides a limited exposure given the anatomical conformation of certain patients and is combined with the resection of the anterior C-1 arch, which destabilizes the atlantoaxial joint and risks its stability. Moreover, endonasal or transoral approaches do not provide a sterile operating environment and may increase the risk of infection. Recently, Agarwal et al. reported a technique of odontoidoplasty and $\mathrm{C}-1$ arch reconstruction from an anterior approach. ${ }^{1}$ In contrast to our technique, these operations must be completed using a second posterior surgery for stabilization.

The dorsolateral approach was first described by Luo et al. in 2000. The same group reported a long-term followup of 25 cases with ventral lesions in the occipitoatlantoaxial region. ${ }^{22}$ Odontoid resections using a lateral occipital condyle approach also have been propagated by other 

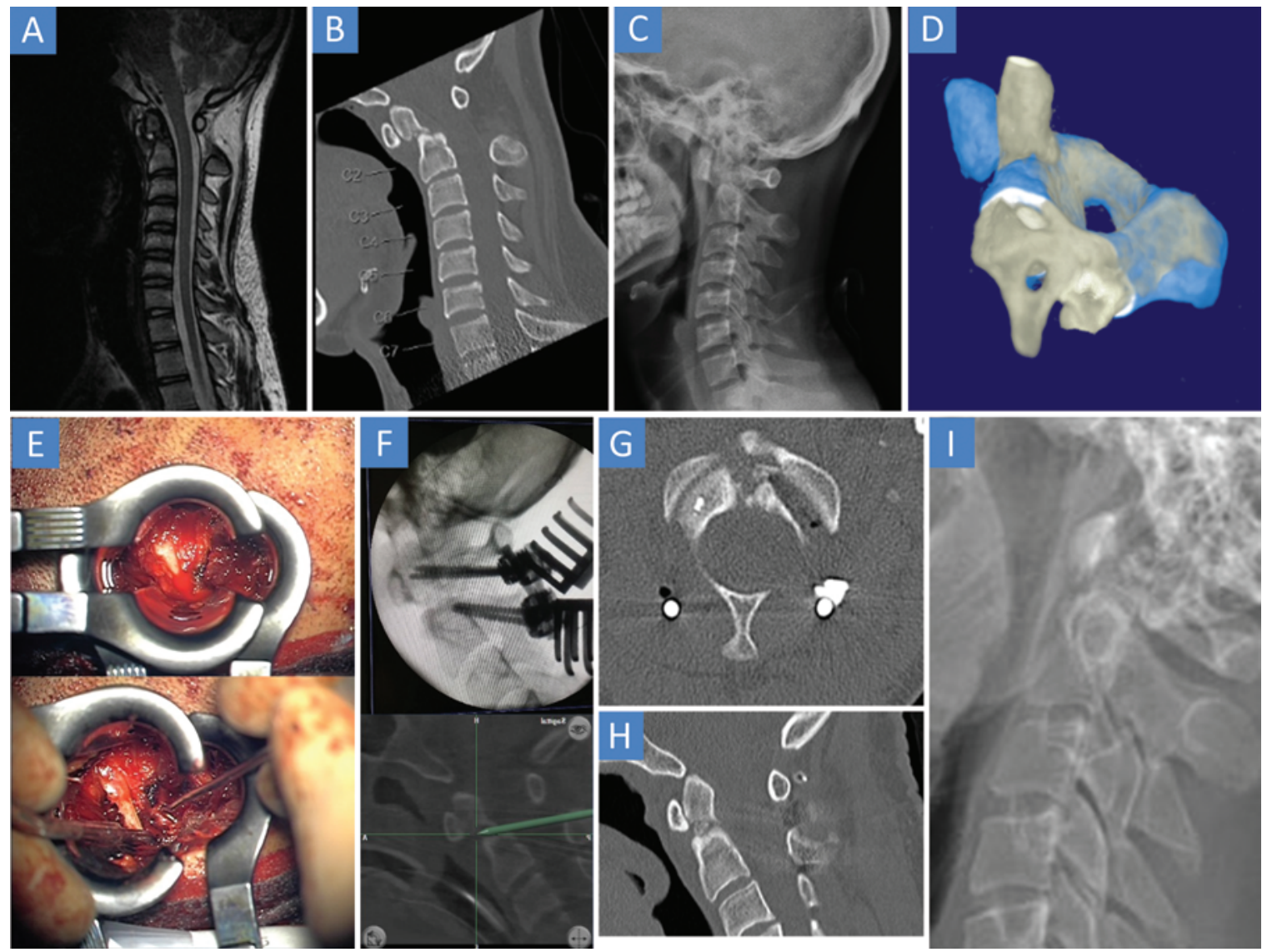

FIG. 3. Case 1. Clinical case of a 23-year-old patient with an odontoid fracture and pseudarthrosis. A: Sagittal T2-weighted MR image from a high-velocity motor vehicle accident 4 years before. B: Sagittal CT scan showing the results of conservative treatment with Philadelphia collar immobilization. C: Sagittal radiograph of C-2 dens pseudarthrosis and high cervical pain with movement. D: Three-dimensional reconstruction study and fusion of CT and MR images on admission, and confirmation of instability. E: Intraoperative photographs of the minimally invasive dorsolateral transmuscular approach to the dens. F: Sagittal intraoperative radiograph (upper) and navigational image (with placement of the tip of the pointer in the pseudarthrosis; lower) showing resection of the pseudarthrosis and augmentation with autologous spongiosa graft. G: Axial CT image demonstrating C1-2 reduction, temporary instrumentation of $\mathrm{C} 1-2$ using the Harms technique, and postoperative confirmation of autologous spongiosa graft in the dens bone defect. H: Sagittal CT image showing excellent clinical outcome, removal of the instrumentation after demonstrated fusion, and the possibility of preservation of function. I: Sagittal radiographic examination of the patient 6 months after surgery showing normal alignment and no suspicion of insufficient bone healing. A CT scan was not considered necessary due to the young age of the patient and the uneventful course.

authors. ${ }^{24,29}$ Frankel et al. reported that if $<50 \%$ of the occipital condyle is removed, stability would not be compromised and fusion would not be necessary. ${ }^{12}$ Through a single surgical approach, the surgeon could have access to decompress and reconstruct the anterior spinal column of the craniocervical junction while also being able to undertake posterolateral fixation and fusion. This allowed access to the dens and the potential for circumferential decompression. However, despite these advantages, the lateral approach requires an extensive exposure with resection of the posterior arch of the atlas, expansion of the foramen magnum, and significant associated soft-tissue morbidity and blood loss. Extraspinal sinusoidal plexus around $\mathrm{CO}-2$ can make surgery very difficult. Türe and Pamir reported good results using the occipitocervical lateral approach for the odontoid resection. ${ }^{32}$ However, this approach required the excision of bone around the lateral mass of $\mathrm{C} 1-2$ and the full exposure of the vertebral artery, increasing the complexity and complication risk of the surgery. The ap- plication of a minimally invasive approach may minimize this tissue trauma.

The feasibility of a minimally invasive approach for posterolateral odontoidectomy has not yet been explored. To the best of our knowledge, this is the first report of a minimally invasive posterolateral partial odontoidectomy. Our tubular approach uses a unilateral oblique approach with minimal resection of the lateral atlantoaxial joint. The anatomical corridor of the approach angle and the associated anatomy are illustrated in Fig. 1. The direction of this approach allows a direct angle to the anterior column. We believe that this allows the surgeon to have an approach for resection of pseudarthrosis and placement of the autologous bone without manipulation of the spinal cord. This approach differs from the recent report of Limin et al. who described a far-lateral exposure with a direct midline approach. ${ }^{22}$ This midline approach better reproduces the familiar anatomy and points of reference. However, it is our opinion that the lateral (and oblique) approach may provide 

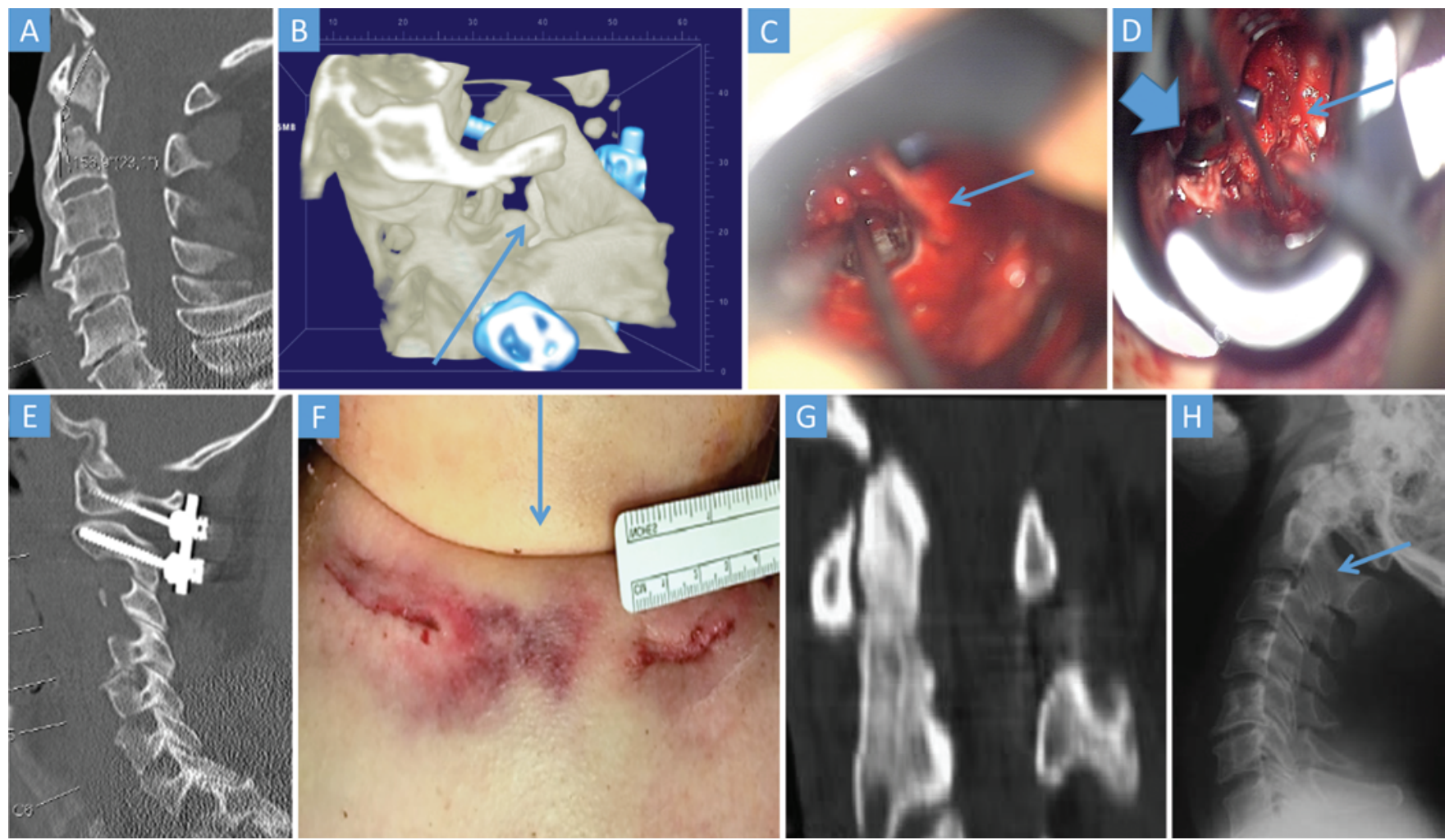

FIG. 4. Case 2. Clinical case of a 35 -year-old patient with an odontoid fracture and pseudarthrosis. A: A preoperative CT scan (sagittal view) shows an Anderson and D'Alonzo Type 2 odontoid fracture. B: Three-dimensional reconstruction of the surgical approach; arrow indicates the operative defect after simulated removal of the pseudarthrotic bone. C: Intraoperative photograph showing the narrow canal of the partial odontoidectomy (arrow points to the myelon). D: Intraoperative photograph after odontoidectomy and placement of the instrumentation; the thin arrow points to the myelon and the thick arrow shows the C-1 lateral mass screw in situ. E: Postoperative CT scan shows satisfactory C1-2 fixation. F: Two paramedian skin incisions are used; on the left for partial odontoidectomy and screw placement and on the right for the mini-open screw placement. The arrow indicates the midline from a cranial direction. G: A sagittal CT scan performed 4 months after autologous bone augmentation shows good fusion. H: Radiograph (sagittal view) showing removal of the instrumentation; the arrow indicates the former position of the screw.

a better view of the ventral elements of the craniocervical junction. As demonstrated in the cadaver study provided in this report, this technique allows for a partial odontoidectomy, namely excision of the dens middle zone without the need for manipulation of the spinal cord. The skin incision and placement of the tubular retractor were planned with 3D virtual reality software. It is important to note that the described approach can access not only ipsilateral but also contralateral pathology. However, direct decompression from within the canal on the side contralateral to the approach corridor may be easier only in selected cases after meticulous surgical planning. The $3 \mathrm{D}$ virtual reality reconstruction study showed that no specific exposure of the vertebral artery is needed. The cadaver study and the 2 clinical cases confirmed these results.

The far-lateral approach is widely regarded as both a time-consuming approach and one commonly associated with significant blood loss. In the small reported cohorts, we did not find any information concerning surgical time and blood loss. However, it is in the authors' own experience that these two parameters may differ significantly between a minimally invasive and far-lateral approach. But even with significant operative times of minimally invasive techniques during the learning curve, decompression and complete instrumentation are completed during a single-stage procedure. Familiarity with other minimally invasive surgical techniques using a similar approach corridor, including the minimally invasive transforaminal lumbar interbody fusion technique and preoperative experience in the cadaver laboratory, may prevent extended operative times.

Reconstruction of the anterior column was performed in all cases with autologous bone. It is important to note that this technique preserves the anterior arch of the atlas. Moreover, in a minimally invasive approach with narrower exposure of the odontoid, no specific exposure of the vertebral artery is required. Lastly, mini-open lateral mass and pedicle screw fixation provides a $360^{\circ}$ temporary arthrodesis. Given the destabilizing potential of the partial odontoidectomy, the contralateral screw-rod fixation is completed initially. However, on the side of the pathology, screw fixation is completed as the final step after excision of the pseudarthrosis.

We believe that this is a safe technique that can be applied by any practicing neurosurgeon comfortable with spinal navigation and minimally invasive tubular techniques. The open combined anterior and posterior operation remains an extensive and technically demanding operation. The use of minimal-access techniques does significantly limit exposed anatomy and places a strong em- 
phasis on fluoroscopy or computer-assisted navigation, but it can be disorienting. In our experience, increasing one's familiarity with the anatomy in the open approach and undergoing significant practice on a cadaver are the primary means for a surgeon to prepare to adopt this technique. We found that 3D simulation could successfully promote our competencies. Furthermore, in cases in which persistent intraoperative challenges are met, such as excessive bleeding or the inability to safely access the dens without compression of the myelon, we have always been prepared to change course intraoperatively to limit the goals of the surgery and continue with the $\mathrm{Cl}-2$ instrumentation.

\section{Conclusions}

A minimally invasive, dorsolateral, tubular odontoidectomy and autologous bone augmentation combined with C1-2 instrumentation has the ability to provide excellent 1-stage management of an odontoid pseudarthrosis with a function-preserving option. The primary goals of this report are to demonstrate the technical aspects of this procedure. Long-term outcomes and larger patient cohorts will provide further clinical data comparing this minimally invasive approach to both anteroposterior surgery, as well as an open, extensive, far-lateral approach. The number of cadavers and patients in this report is small, and further experience with this technique will help to validate its efficacy.

\section{Acknowledgments}

Computed tomographic images were kindly provided by Prof. Müller-Forell, Institute of Neuroradiology, University Medical Center, Johannes Gutenberg-University Mainz, Germany.

\section{References}

1. Agrawal A, Reyes PM: A novel technique of odontoidoplasty and $\mathrm{C} 1$ arch reconstruction: anatomical and biomechanical basis. Neurosurgery 68 (1 Suppl Operative):103-113, 2011 (Erratum in Neurosurgery 68:1511, 2011)

2. Apfelbaum RI, Lonser RR, Veres R, Casey A: Direct anterior screw fixation for recent and remote odontoid fractures. J Neurosurg 93 (2 Suppl):227-236, 2000

3. Archavlis E, Carvi y Nievas M: Comparison of minimally invasive fusion and instrumentation versus open surgery for severe stenotic spondylolisthesis with high-grade facet joint osteoarthritis. Eur Spine J 22:1731-1740, 2013

4. Blauth M, Richter M, Kiesewetter B, Lange U: [Operative versus non operative treatment of odontoid non unions. How dangerous is it not to stabilize a non union of the dens?] Chirurg 70:1225-1238, 1999 (Ger)

5. Böhler J: Anterior stabilization for acute fractures and nonunions of the dens. J Bone Joint Surg Am 64:18-27, 1982

6. Brooks AL, Jenkins EB: Atlanto-axial arthrodesis by the wedge compression method. J Bone Joint Surg Am 60:279284, 1978

7. Chiba K, Fujimura Y, Toyama Y, Fujii E, Nakanishi T, Hirabayashi K: Treatment protocol for fractures of the odontoid process. J Spinal Disord 9:267-276, 1996

8. Crockard HA, Heilman AE, Stevens JM: Progressive myelopathy secondary to odontoid fractures: clinical, radiological, and surgical features. J Neurosurg 78:579-586, 1993

9. Duntze J, Eap C, Kleiber JC, Théret E, Dufour H, Fuentes S, et al: Advantages and limitations of endoscopic endonasal odontoidectomy. A series of nine cases. Orthop Traumatol Surg Res 100:775-778, 2014
10. Esses SI, Bednar DA: Screw fixation of odontoid fractures and nonunions. Spine (Phila Pa 1976) 16 (10 Suppl):S483S485, 1991

11. Fairholm D, Lee ST, Lui TN: Fractured odontoid: the management of delayed neurological symptoms. Neurosurgery 38:38-43, 1996

12. Frankel BM, Hanley M, Vandergrift A, Monroe T, Morgan S, Rumboldt Z: Posterior occipitocervical $(\mathrm{CO}-3)$ fusion using polyaxial occipital condyle to cervical spine screw and rod fixation: a radiographic and cadaveric analysis. J Neurosurg Spine 12:509-516, 2010

13. Gallie W: Fractures and dislocations of the cervical spine. Am J Surg 46:495, 1939

14. Grauer JN, Vaccaro AR, Beiner JM, Kwon BK, Hilibrand AS, Harrop JS, et al: Similarities and differences in the treatment of spine trauma between surgical specialties and location of practice. Spine (Phila Pa 1976) 29:685-696, 2004

15. Hadley MN, Dickman CA, Browner CM, Sonntag VK: Acute axis fractures: a review of 229 cases. J Neurosurg 71:642647, 1989

16. Harms J, Melcher RP: Posterior C1-C2 fusion with polyaxial screw and rod fixation. Spine (Phila Pa 1976) 26:2467-2471, 2001

17. Jeanneret B, Magerl F: Primary posterior fusion $\mathrm{C} 1 / 2$ in odontoid fractures: indications, technique, and results of transarticular screw fixation. J Spinal Disord 5:464-475, 1992

18. Jeanneret B, Vernet O, Frei S, Magerl F: Atlantoaxial mobility after screw fixation of the odontoid: a computed tomographic study. J Spinal Disord 4:203-211, 1991

19. Kantelhardt SR, Keric N, Conrad J, Archavlis E, Giese A: Minimally invasive instrumentation of uncomplicated cervical fractures. Eur Spine J 25:127-133, 2016

20. Lapsiwala SB, Anderson PA, Oza A, Resnick DK: Biomechanical comparison of four $\mathrm{C} 1$ to $\mathrm{C} 2$ rigid fixative techniques: anterior transarticular, posterior transarticular, $\mathrm{C} 1$ to $\mathrm{C} 2$ pedicle, and $\mathrm{C} 1$ to $\mathrm{C} 2$ intralaminar screws. Neurosurgery 58:516-521, 2006

21. Lee PC, Chun SY, Leong JC: Experience of posterior surgery in atlanto-axial instability. Spine (Phila Pa 1976) 9:231-239, 1984

22. Limin L, Chunguang Z, Yueming S, Siqing H, Hao L, Quan $\mathrm{G}$, et al: A posterolateral approach to occipitoatlantoaxial ventral lesions: a report of the long-term follow-up of 23 cases. J Spinal Disord Tech 26:281-290, 2013

23. Maak TG, Grauer JN: The contemporary treatment of odontoid injuries. Spine (Phila Pa 1976) 31 (11 Suppl):S53-S61, 2006

24. McLoughlin GS, Sciubba DM, Suk I, Bydon A, Witham T, Wolinsky JP, et al: Resection of a retropharyngeal craniovertebral junction chordoma through a posterior cervical approach. J Spinal Disord Tech 23:359-365, 2010

25. Moskovich R, Crockard HA: Myelopathy due to hypertrophic nonunion of the dens: case report. J Trauma 30:222-225, 1990

26. Paradis GR, Janes JM: Posttraumatic atlantoaxial instability: the fate of the odontoid process fracture in 46 cases. J Trauma 13:359-367, 1973

27. Ruf M, Welk T, Müller M, Merk HR, Harms J: Ventral cancellous bone augmentation of the dens and temporary instrumentation $\mathrm{C} 1 / \mathrm{C} 2$ as a function-preserving option in the treatment of dens pseudarthrosis. J Spinal Disord Tech 23:285-292, 2010

28. Ryan MD, Taylor TK: Odontoid fractures in the elderly. J Spinal Disord 6:397-401, 1993

29. Sen C, Shrivastava R, Anwar S, Triana A: Lateral transcondylar approach for tumors at the anterior aspect of the craniovertebral junction. Neurosurgery 66 (3 Suppl):104-112, 2010 
30. Stillerman CB, Wilson JA: Atlanto-axial stabilization with posterior transarticular screw fixation: technical description and report of 22 cases. Neurosurgery 32:948-955, 1993

31. Subach BR, Morone MA, Haid RW Jr, McLaughlin MR, Rodts GR, Comey CH: Management of acute odontoid fractures with single-screw anterior fixation. Neurosurgery 45:812-820, 1999

32. Türe U, Pamir MN: Extreme lateral-transatlas approach for resection of the dens of the axis. J Neurosurg 96 (1 Suppl):73-82, 2002

33. Vaccaro AR, Madigan L, Ehrler DM: Contemporary management of adult cervical odontoid fractures. Orthopedics 23:1109-1115, 2000

34. Wang C, Yan M, Zhou HT, Wang SL, Dang GT: Open reduction of irreducible atlantoaxial dislocation by transoral anterior atlantoaxial release and posterior internal fixation. Spine (Phila Pa 1976) 31:E306-E313, 2006

\section{Disclosures}

The authors report no conflict of interest concerning the materi- als or methods used in this study or the findings specified in this paper.

\section{Author Contributions}

Conception and design: Archavlis, Giese. Acquisition of data: Archavlis, Serrano, Schwandt, Molina-Fuentes. Analysis and interpretation of data: Archavlis. Drafting the article: Archavlis. Critically revising the article: Archavlis, Serrano, Nimer, MolinaFuentes, Rahim, Gutenberg, Kantelhardt. Reviewed submitted version of manuscript: Archavlis, Serrano, Schwandt, Nimer, Ackermann, Rahim, Gutenberg, Kantelhardt, Giese. Approved the final version of the manuscript on behalf of all authors: Archavlis. Administrative/technical/material support: Ackermann.

\section{Correspondence}

Eleftherios Archavlis, Department of Neurosurgery, University Medical Centre, Johannes Gutenberg-University Mainz, Langenbeckstrasse 1, D 55131 Mainz, Germany. email: neurosurgery@ t-online.de. 